\title{
Oxide and Hydroxide Activity Determination in Oxide Doped Lithium Fluoride
}

\author{
G. Trevisan * and S. Pizzini * \\ EURATOM C.C.R. PETTEN, Materials Department Electrochemistry Group * \\ (Z. Naturforschg. 22 a, 651-654 [1967] ; received 25 February 1967)
}

\begin{abstract}
Oxide and hydroxide activities in solid lithium fluoride at high temperatures have been evaluated by measuring the equilibrium partial pressures of water and hydrofluoric acid.

Results concerning the lithium hydroxide solubility have been discussed on the basis of the phase diagram of the $\mathrm{LiF}-\mathrm{LiOH}$ system and the concentration of the dissolved lithium hydroxide has been calculated.
\end{abstract}

The aim of the present paper is the quantitative evaluation of the activities of lithium oxide and hydroxide in solid lithium fluoride samples in the range of the extremely diluted solutions, which result from the doping due to pyrohydrolytic reactions as well as to thermal decomposition of carbonate always present in trace amount in the lithium fluorides.

The determination of activities of oxides and hydroxides in solid halides requires in principle the measurement either of their chemical potential by means of a suitable electrochemical method, or of the chemical potential of water and hydrofluoric acid, or of the chemical potential of oxide and hydroxide in the vapor phase.

E. M. F. measurements on solid galvanic chains of the type

$\mathrm{Pt} / \mathrm{Me} / \mathrm{MeO} \mathrm{c}_{1}(\mathrm{LiF}) / \mathrm{ZrO}_{2}+\mathrm{CaO} / \mathrm{MeO} \mathrm{c}_{2}(\mathrm{LiF}) / \mathrm{Me} / \mathrm{Pt}$

permit only the determination of the chemical potential of the dissolved oxide.

Moreover, lithium oxide, present at reduced activity in the solid solution, could not easily be detected by high temperature mass-spectrometric methods ${ }^{1}$ at temperatures below $840{ }^{\circ} \mathrm{C}$, the vapor pressure of the pure solid being about $2 \cdot 10^{-7}$ torr at $975^{\circ} \mathrm{C}^{2}$.

Nevertheless by utilizing the known values of the equilibrium constants of the reactions ${ }^{3}$ :

$$
\begin{array}{ll}
\mathrm{Li}_{2} \mathrm{O}(\mathrm{s})+\mathrm{H}_{2} \mathrm{O}(\mathrm{g}) & \rightleftarrows 2 \mathrm{LiOH}(\mathrm{g}), \\
\mathrm{LiOH}(\mathrm{s}) & \rightleftarrows \mathrm{LiOH}(\mathrm{g})
\end{array}
$$

the equilibrium partial pressure of lithium oxide and hydroxide could be detected by controlling the water partial pressure in a KNUDSEN cell.

\footnotetext{
* Present adress: Euratom C.C.R., Ispra, Italy.

1 The ultimate sensitivity of the Knudsen cell-Mass spectrometric method lies in the range $1 \times 10^{-8}-1 \times 10^{-9}$ torr.
}

In order to avoid the experimental difficulties involved in the previously mentioned methods, we have decided to carry out measurements of partial pressures of water and hydrofluoric acid, considering that the water and hydrofluoric partial pressures are functionally dependent on the lithium hydroxide and oxide activities, according to the following relationships :

$$
\begin{aligned}
& a_{\mathrm{LiOH}}=K_{1} / Q \\
& a_{\mathrm{Li} 20}=K_{1}^{2} K_{\mathbf{2}} / Q P_{\mathrm{HF}}
\end{aligned}
$$

where: $Q=P_{\mathrm{IIF}} / P_{\mathrm{H} 2 \mathrm{O}}$ and $K_{1}, K_{2}$ are the equilibrium constants of the two independent reactions:

$$
\begin{array}{ll}
\mathrm{LiF}(\mathrm{s})+\mathrm{H}_{2} \mathrm{O}(\mathrm{g}) & \rightleftarrows \mathrm{LiOH}(\mathrm{d})+\mathrm{HF}(\mathrm{g}), \\
2 \mathrm{LiOH}(\mathrm{d}) & \rightleftarrows \mathrm{Li}_{2} \mathrm{O}(\mathrm{d})+\mathrm{H}_{2} \mathrm{O}(\mathrm{g}) .
\end{array}
$$

\section{Experimental}

Measurements of water and hydrofluoric acid partial pressures in equilibrium with oxide and hydroxide-containing lithium fluoride samples have been carried out by means of a static method.

As partial pressure gauge an Omegatron type mass spectrometer has been used, which was operated in the range $3 \cdot 10^{-9}-3 \cdot 10^{-6}$ torr.

The apparatus (see Fig. 1) consists essentially of an all glass and fused silica vacuum system that includes a reaction chamber and pressure gauges and is bakeable at $450^{\circ} \mathrm{C}$. The system can be fully isolated during experiments from the pumping unit by means of an all glass electromagnetically operated valve.

\footnotetext{
2 J. Berkowitz, W. A. Chupka, G. D. Blue, and J. L. Margrave, J. Chem. Phys. 63, 644 [1959].

3 J. Berkowitz, D. J. Meschi, and W. A. Chupka, J. Chem. Phys. 33, 533 [1960].
} 
The reaction chamber is a double walled fused silica vessel which contains a platinum crucible with the sample.

The crucible is heated by means of an external resistance oven and the temperature is kept constant within $\pm 1{ }^{\circ} \mathrm{C}$ in short-times runs. In the jacket a vacuum of $1 \cdot 10^{-3}$ torr is maintained. Two pressure gauges, the Omegatron and the ionization gauge are sealed to the manifold (see Fig. 1) with tubes of the same length and diameter.

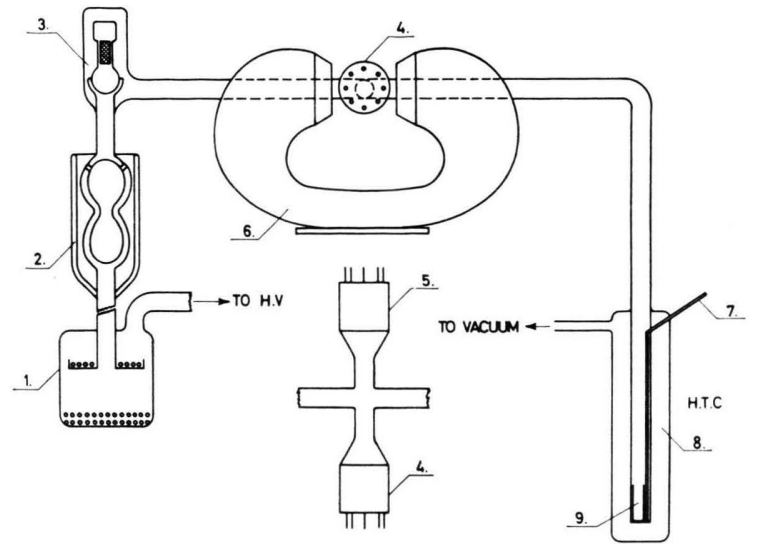

Fig. 1. Schematic view of the apparatus used for the determination of partial pressures of $\mathrm{H}_{2} \mathrm{O}$ and HF. 1. Molecular Sieves trap; 2 . Liquid nitrogen trap; 3 . Electromagnetically operated all glass valve; 4 . Omegatron gauge; 5 . Ionization gauge; 6 . Permanent magnet; 7. Thermocouple; 8. Jacket; 9. Pt crucible; HTC silica high temperature cell.

The vacuum system consists of an all glass oil diffusion pump, a Biondr type Molecular Sieves trap and a liquid nitrogen trap. An auxiliary vacuum line, which consists of a water reservoire and a U. H. V. variable leak valve, allows the water partial pressure to be varied in the system (the manifold of the variable leak valve is sealed between the all glass and the liquid nitrogen trap). The sample, after the preliminary bakeout of the whole vacuum system, is heated by steps at a fixed temperature ranging between 550 and $740{ }^{\circ} \mathrm{C}$ and pumped down to complete exhaustion. The exhaustion of the sample at the experimental temperature was considered complete when the ultimate total pressure was in the range $3 \cdot 10^{-9}-1 \cdot 10^{-8}$ torr, and the pressure increasing rate in the fully isolated system was not exceeding the $30 \%$ of the initial pressure in a time of the order of $15 \mathrm{~min}$.

4 A. Klopfer and W. Schmidt, Vacuum 10, 363 [1960].

${ }^{5}$ H. Gentsch, Vorträge des 2. Europäischen Symposiums „Vakuum“, R. A. Lang Verlag, Frankfurt (Main) 1963.
In the experimental conditions $\mathrm{SiF}_{4}$ has been never detected, within the limit of sensitivity of the Omegatron, which is of the order of $10^{-10}$ torr.

This indicates that if the reaction between hydrofluoric acid and silicon oxide occurs, the amount of hydrofluoric acid substracted from equilibrium by the parasitic reaction, is negligibly small. As for the absorption of hydrofluoric acid and water on the walls, it has been observed that saturation of the walls is required in order to get reproducible results. This means that when the walls of the manifold are baked out and experiments are carried out without a sufficient delay, the ratios $P_{\mathrm{HF}} / P_{\mathrm{H} 2 \mathrm{O}}$ diverge significantly from that measured under the same conditions after saturation.

It is well known that the Omegatron gauge (like every kind of I. G.) does not measure pressures but only ionic currents which are nevertheless proportional (under certain conditions ${ }^{4}$ that we assume to be completely fulfilled in our experiments) to the pressures, according to the relationship:

where:

$$
i_{+}=i_{-} S_{i} p
$$

$i_{+}=$ionic current,

$i_{-}=$electronic current,

$S_{i}=$ sensitivity of the gauge for the species $i$,

$p=$ pressure.

Furthermore it has been demonstrated by GeNTsCH ${ }^{5}$ that in a real Omegatron the sensitivity is a function of the pressure. An ionization gauge has been indeed taken as a pressure reference ${ }^{6}$, and the experiments have been carried out by simultaneous monitoring of both total pressure and partial ionic currents.

From the relationships

$$
\begin{aligned}
P_{\mathrm{T}} & =\sum_{i=1}^{n} p_{i}, \\
p_{i} & =i_{i} / i_{-} S_{i}
\end{aligned}
$$

(where $P_{\mathrm{T}}=$ total pressure, $p_{i}=$ partial pressure of the species $i$ and $i_{i}=$ ionic current of the species $i$ ), it follows that:

$$
P_{\mathrm{T}}=\sum_{i=1}^{n} \frac{i_{i}}{i_{-} S_{i}} .
$$

As $S_{i}$ is proportional to the ionization cross section:

$$
S_{i}=K \sigma_{i}
$$

6 The I.G. is a Varian U.H.V. 12 P model. The Varian firm guarantes the calibration for the more common U.H.V. gases within $\pm 20 \%$. 
(where $\sigma_{i}$ is the OTvos' ${ }^{7}$ cross section of the species $i$ ) only the value of the $K$ for the Omegatron gauge is required in order to calculate the partial pressure.

By assuming (as a crude approximation, which nevertheless does not hardly influence the partial pressure calculation) that the $P_{\mathrm{T}}$ values are equal to the I. G. readings, $K$ is calculated at the actual experimental pressure by means of the OTvos' ionization cross section.

As the measurements had been carried out with the pressure gauges at room temperature, the experimental values had been corrected for the thermal transpiration effect ${ }^{8}$ according to the relationship:

$$
p_{1} / p_{2}=\sqrt{T_{1} / T_{2}}
$$

where the subscription 1 refers to the cold zone and the subscription 2 refers to the hot zone.

\section{Results and Discussion}

Activities of lithium hydroxide and lithium oxide have been calculated according to Eqs. (2) and (3) and have been plotted in Fig. 2 and 3, in activities vs. water partial pressure diagrams. (The values of $K_{1}$ and $K_{2}$ have been obtained from JanaF Tables ${ }^{9}$.)

From these diagrams, if the activity coefficients are known, it is possible to calculate the corresponding lithium hydroxide and oxide concentrations as a function of the water partial pressure.

It is to be remarked here that the lithium oxide activities as calculated from Eq. (3) suffer from the uncertainty inherent in the hydrofluoric acid absolute pressure determination, while the lithium hydroxide ones result from the partial ionic current ratios and are indeed independent of the absolute pressure.

As for the lithium hydroxide, information on the activity coefficient in the saturated solid solution can be drawn from Scarpa's ${ }^{10}$ phase diagram if the liquid solution is ideal.

In order to check the behaviour of the liquid solution, the theoretical liquidus curve has been calculated by assuming that the lithium fluoride activity equals its concentration (Fig. 4). It is apparent (see also Lumsden ${ }^{11}$ ) that the theoretical and Scarpa's

7 J. W. Otvos and D. P. Stevenson, J. Amer Chem. Soc. 78, 546 [1956].

8 A. H. Turnbull, R. S. Barton, and J. C. Riviere, An Introduction to Vacuum Technique, G. Newnes Ltd., London 1962.

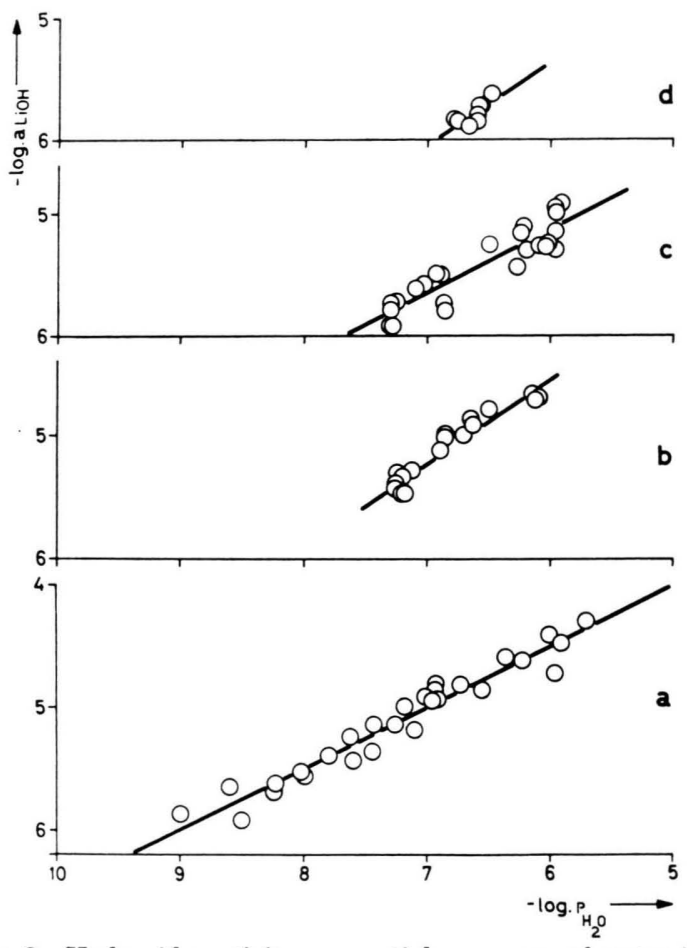

Fig. 2. Hydroxide activity vs. partial pressures of water isotherms. a) $T=869^{\circ} \mathrm{K}$; b) $T=931^{\circ} \mathrm{K}$; c) $T=985^{\circ} \mathrm{K}$; d) $T=1034^{\circ} \mathrm{K}$. Isotherms have been drawn by means of the last square method.

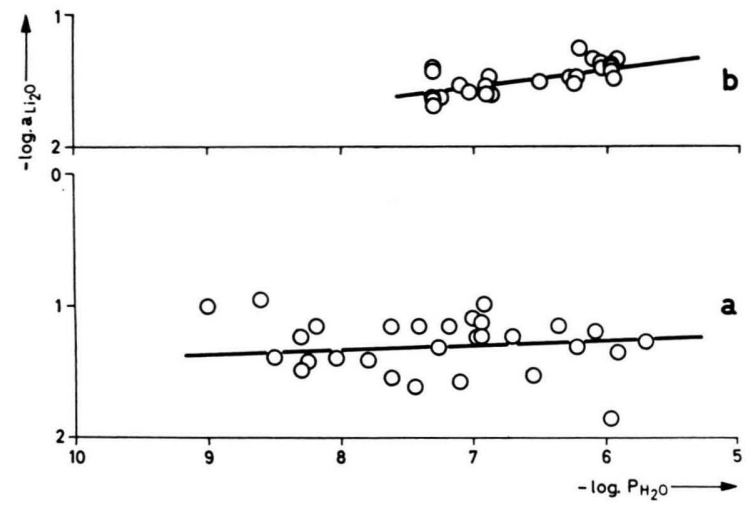

Fig. 3. Oxide activity vs. partial pressure of water isotherms. a) $T=869^{\circ} \mathrm{K}$; b) $T=985^{\circ} \mathrm{K}$.

experimental curves fit very closely at least between 840 and $605{ }^{\circ} \mathrm{C}$. We conclude that in this temperature range the behaviour of the liquid solution is ideal.

9 JANAF Thermochemical Data, The Dow Chemical Company, Thermal Laboratory, Middland, Michigan 1961.

10 G. Scarpa, Atti Accad. Naz. Lincei Rend. 24-II Sem. V Serie - 476 [1915].

11 J. Lumsden, Thermodynamics of Molten Salt Mixtures, Academic Press, London 1966. 


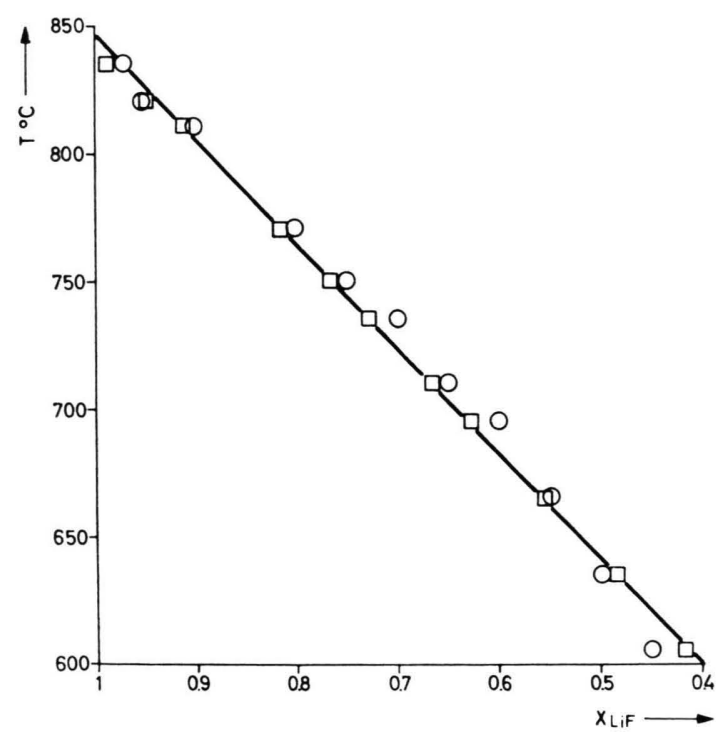

Fig. 4. Experimental ${ }^{10}$ and calculated liquidus curves for the system $\mathrm{LiF}-\mathrm{LiOH}, \bigcirc$ experimental, $\square$ calculated.

Under this assumption the activity coefficient $\gamma$ for the saturated solid solution can be calculated by equating the chemical potentials of the lithium hydroxide in the solid and liquid solutions, according to the relationships:

$$
\begin{aligned}
& \mu_{\mathrm{LiOH}}^{(1)}=\mu_{\mathrm{LiOH}}^{(\alpha) \text { (sat) }} \\
& \mu_{\mathrm{LiOH}}^{(\mathrm{l})}+R T \ln X_{\mathrm{LiOH}}^{(\mathrm{l})}=\mu_{\mathrm{LiOH}}^{0(\mathrm{~s})}+R T \ln X_{\mathrm{LiOH}}^{(\alpha)}(\mathrm{sa}) \\
& +R T \ln \gamma \text {, } \\
& \ln \gamma_{\mathrm{LiOH}}=\frac{\mathrm{G}_{\mathrm{LiOH}}^{\mathrm{O}(1)}-\mathrm{G}_{\mathrm{LiOH}}^{\mathrm{O}(\mathrm{s})}}{R T}+\ln X_{\mathrm{LiOH}}^{(1):}-\ln X_{\mathrm{LiOH}}^{(\alpha)}{ }^{(\text {sat })}
\end{aligned}
$$

where $\alpha$ indicate the solid solution, 1 the liquid solution, $X$ is the molar fraction and $\gamma$ and $G$ have their usual significance. If we choose a point at the boundary of the solid solution phase in the Scarpa's diagram, namely:

$$
T=740{ }^{\circ} \mathrm{C}, \quad \begin{gathered}
X_{\mathrm{LiOH}}^{(\alpha)}{ }_{(\text {sat })}^{(1)}=2.5 \times 10^{-2}, \\
X_{\mathrm{LiOH}}^{(1)}=3 \times 10^{-1}
\end{gathered}
$$

an activity coefficient of 4,8 is obtained.

Although the $\gamma$ vs. $X$ relationship is unknown at concentrations lower than that of saturation, we could assume that in the range of $10^{-5}-10^{-6}$ (in activity units) the activity coefficients drops to one.

It results that the $a_{\mathrm{LiOH}}$ vs. $p_{\mathrm{H} 20}$ plot of Fig. 2 coincides with a $X_{\mathrm{LiOH}}$ vs. $p_{\mathrm{H} 2 \mathrm{O}}$ one.

For the matter of lithium oxide, if we assume that the hydrofluoric partial pressure is known within a factor of $2-3$, the resulting lithium oxide activity is affected by an error of about one order of magnitude.

Within this experimental error, results of Fig. 3 are accounted for a solid state solubility of lithium oxide which never exceeds the saturation value. Unfortunately, as phase diagram data on the system $\mathrm{Li}_{2} \mathrm{O}-\mathrm{LiF}$ are not available in the literature and Haven's ${ }^{12}$ data on the same system only suggest a small solid state solubility, the activity coefficients of lithium oxide cannot be calculated in a similar way as those of lithium hydroxide.

Work is however in progress in order to determine independently (via activation analysis) the total oxygen content, which should help to the complete knowledge of the system under investigation.

12 Y. Haven, Rec. Trav. Chim. 69, 1505 [1950]. 